\title{
Detection of Fetal Aneuploidies by QF-PCR in Transcervical Cell Samples
}

\author{
Riccardo Cioni, Cecilia Bussani, and Mariarosaria Di Tommaso
}

Maternity Ward, Careggi University Hospital, Largo Brambilla 3, 50134 Florence, Italy

Correspondence should be addressed to Riccardo Cioni, rcioni@yahoo.it

Received 10 November 2012; Accepted 3 December 2012

Academic Editors: K.-M. Hsiao, D. Radojkovic, and A. Yamamoto

Copyright (C) 2013 Riccardo Cioni et al. This is an open access article distributed under the Creative Commons Attribution License, which permits unrestricted use, distribution, and reproduction in any medium, provided the original work is properly cited.

\begin{abstract}
Objective. To evaluate the accuracy in the diagnosis of aneuploidies of a quantitative fluorescent polymerase chain reaction (QFPCR) assay on trophoblastic cells recovered from transcervical cells samples (TCCs) collected by intrauterine lavage (IUL). Study Design. DNA analysis was performed on cells of seemingly trophoblastic origin isolated from IUL samples collected prior to first trimester termination of pregnancy. The analysis was performed by multiplex QF-PCR, using a panel of 29 polymorphic short tandem repeats (STRs) for the chromosomes X, Y, 21, 13, and 18. Results. The QF-PCR analysis on placental samples revealed that among the three cases studied there were two cases of trisomy 21 and one case of monosomy X; the comparison of peak profiles obtained from IUL, placental, and maternal samples confirmed the diagnosis of aneuploidy in all three cases. Conclusion. This study suggests that the detection of chromosomal aneuploidies in micromanipulated TCC samples can be achieved by QF-PCR amplification of selected highly polymorphic and chromosome specific markers. With respect to standard karyotype, QF-PCR analysis has the limitation that only numerical abnormalities of selected chromosomes can be detected but retains the advantages of being quicker, less expensive, and less lab demanding.
\end{abstract}

\section{Introduction}

Currently chorionic villus sampling (CVS) and amniocentesis are the main methods for prenatal genetic diagnosis. Both these procedures are invasive and have been associated with a risk of pregnancy loss of $1 \%$ [1]; also, cells need to be cultured for the obtainment of a karyotype, and two weeks are commonly required before the results can be made available to the pregnant woman. A further problem with amniocentesis is that the technique is performed at 16-18 weeks' gestation, and this results in the late termination of affected pregnancies with a more traumatic method and an evident psychological distress.

For these reasons the attainment of prenatal genetic diagnosis by mini-invasive techniques has been extensively studied in recent years; both fetal cells and cell-free DNA have been found in the maternal circulation, but clinical implications are limited thus far to the prediction of fetal sex and Rh status $[2,3]$.

In a different line of research it has been attempted to detect trophoblastic cells in transcervical cell (TCC) samples.
Following the pioneering study by Shettles [4] who first claimed he could accurately predict fetal sex by simply observing the "Y-body fluorescence" on quinacrine-stained mucus samples collected from the cervix, many groups have reported on the successful prediction of fetal sex and prenatal genetic diagnosis using trophoblastic cells from TCC samples. Overall the results of these studies show very different figures as to the rates of correct sex prediction and genetic diagnosis, and this is probably due to the diverse techniques used both for sample collection and analysis. Indeed, TCC sampling may involve either the collection of the mucus plug (by cytobrush or by aspiration) or the flushing of the lower genital tract at various levels (endocervix, uterine cavity), and it is now clear that these procedures do differ in terms of trophoblastic cell yield, since the reported rates of correct sex prediction are $24-70 \%$ for mucus samples $[5,6]$ and $75-91 \%$ for intrauterine lavage samples $[7,8]$. With respect to the methods used for the analysis, an important limitation of most previous studies is that they were simply intended for demonstrating the presence of trophoblastic cells within the samples, and an aim pursued using either fluorescence 
in situ hybridisation (FISH) or PCR-based assays to detect $\mathrm{Y}$ chromosome sequences in samples from male fetuses [5]. However, if the clinical use of these samples for prenatal genetic diagnosis is concerned, trophoblastic cells must not only be detected but also isolated in view of subsequent genetic analysis; in this respect, recent studies by our group show that intrauterine lavage (IUL) samples, unlike mucus samples, often contain trophoblastic cells to such an extent to enable easy detection and isolation [9-11].

In recent years, the availability of the quantitative fluorescent polymerase chain reaction (QF-PCR) assay has contributed greatly to the investigation of TCC samples for prenatal diagnostic purposes. The QF-PCR technique relies on the amplification of chromosome-specific short tandem repeat (STR) sequences using fluorescent primers, whereas the analysis of the products of amplification is performed using an automated DNA sequencer. Usually STRs with high degree of polymorphism are used, and more than one STRs for each single autosomal chromosome are investigated at any one time in order to achieve informative results on the chromosome copy number; while the lack of highly polymorphic markers had hindered the detection of sex chromosome abnormalities until a few years ago, in recent times many of these markers have been identified, and the QF-PCR analysis of all numerical sex chromosome disorders has finally became possible [12].

The aim of the present investigation was to evaluate the accuracy in the diagnosis of aneuploidies of a QF-PCR assay on trophoblastic cells recovered from TCCs collected by IUL.

\section{Materials and Methods}

We analysed three IUL samples collected prior to first trimester termination of pregnancy (TOP), requested for increased aneuploidy risk following nuchal translucency measurement. None of the women had undergone an invasive prenatal diagnostic procedure before TOP. All the women gave their informed consent.

With the woman in the lithotomy position, under general anesthesia, a speculum was inserted to visualize the cervix which was disinfected with an iodine solution, and IUL was then performed using a $2.5 \mathrm{~mm}$ inner diameter flexible catheter (Nelaton Catheter; Medinorm, Quierschied, Germany) attached to a syringe filled with $10 \mathrm{~mL}$ of sterile saline solution. The catheter was carefully inserted through the cervical canal, just past the internal os; the saline was instilled under gentle pressure and then $2-6 \mathrm{~mL}$ (mean value $3.5 \mathrm{~mL}$ ) were aspirated back after 10 seconds.

Shortly after collection, IULs were transferred into a Petri dish and observed under inverted microscope: cells clumps and villous filaments of seeming trophoblastic origin (Figure 1) were isolated using a pipette with sterile-plugged tip, washed in sterile saline solution, and cut in a separate dish with $2 \mathrm{~mL}$ of sterile saline solution. From each sample a maximum of $10 \mathrm{mg}$ of villi were prepared for DNA extraction.

A fragment of placental tissue was collected at TOP in all cases, as well as a sample of peripheral blood from the mother. Placental tissue samples were also observed under an inverted microscope to select chorionic villi (about $10 \mathrm{mg}$ ) for DNA extraction.

2.1. QF-PCR Procedure. DNA was extracted from the micromanipulated IUL, from placental tissue, and from $200 \mathrm{uL}$ of peripheral blood samples, using an automated system (Biorobot EZ1, QIAGEN SpA, Milan, Italy), with a DNA yield of 15-20 ug for tissues and up to $8 \mathrm{ug}$ for blood. For the QFPCR analysis of the chromosomes X, Y, 21, 18, and 13, a panel of 29 STR markers (listed in Table 1) were selected on the basis of their highly polymorphic nature.

Fetal sex was assessed using the nonpolymorphic sequence of the amelogenin region (AMXY), which corresponds to two different specific products for the $\mathrm{X}$ and the $\mathrm{Y}$ chromosomes (104 bp and $109 \mathrm{bp}$, resp.); two additional sex chromosome markers were used: the pentanucleotide repeat $\mathrm{X} 22$, which maps to pseudoautosomal region (PAR2) of the $\mathrm{X}$ and $\mathrm{Y}$ chromosomes and the $\mathrm{X}$-linked hypoxanthine phosphoribosyltransferase (HPRT), amplified together with the D21S1411 as an autosomal internal control for its quantification, to distinguish between a normal female fetus homozygous for all X markers and a monosomy $\mathrm{X}$ fetus [13].

All reactions were set up in a final volume of $25 \mathrm{uL}$ containing $10 \mathrm{ng}$ of DNA, $200 \mathrm{umol} / \mathrm{L}$ dNTP, 2-25 pmol of primer, $2 \mathrm{mmol} / \mathrm{L} \mathrm{MgCl}_{2}$ in $1 \mathrm{x}$ Taq buffer, and $1 \mathrm{U}$ of Taq polymerase (AmpliTaq Gold, Applied Biosystems, Foster City, CA, USA). After denaturation for $2 \mathrm{~min}$ at $95^{\circ} \mathrm{C}$ (hot start procedure) the samples were subjected to 28 cycles of amplification $\left(35 \mathrm{~s}\right.$ at $94^{\circ} \mathrm{C}, 1.30 \mathrm{~min}$ at $58^{\circ} \mathrm{C}, 1 \mathrm{~min}$ at $72^{\circ} \mathrm{C}$, plus a final extension of $15 \mathrm{~min}$ at $72^{\circ} \mathrm{C}$ ) in a programmable thermal controller machine (PTC-100, MJ research, Watertown, MA, USA). One uL of $1: 10$ diluted QF-PCR products, mixed to $12 \mathrm{uL}$ of formamide and $0.3 \mathrm{uL}$ of size standard (TAMRA 500, Applied Biosystems, Foster City, CA), was separated, after 3 min of denaturation, in an ABI Prism 310 automated genetic analyser (Applied Biosystems, Foster City, CA, USA). All forward primers were fluorescently labelled for the assessment of the size and the amount of the PCR products. Analysis of the results was performed with GeneScan software 3.1 (Applied Biosystems, Foster City, CA, USA).

\section{Results}

In all three cases chorionic villi and/or cells clumps of seeming trophoblastic origin could be detected and sorted by micromanipulation under inverted microscope, at which time the samples were also checked for possible sperm contamination that could be ruled out in all cases.

The QF-PCR analysis on placental samples revealed that among the three cases studied there were two cases of trisomy 21 and one case of monosomy X; the same findings were documented also in micromanipulated IULs, where the peak pattern obtained precisely matched that of the corresponding placental samples, thus confirming the trophoblastic origin of the cells selected from IULs (Figure 2). In addition, the comparison of peak profiles obtained from IUL, placental, and maternal blood samples was useful to clarify the inheritance of the various STR alleles used in 


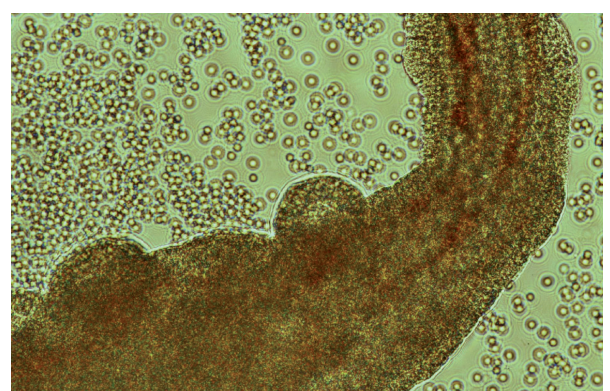

(a)

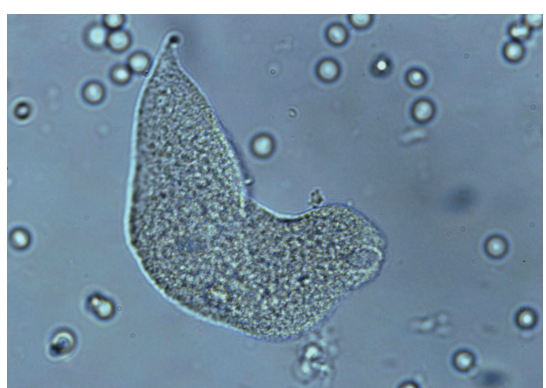

(b)

FIGURE 1: Villus (a) and trophoblastic cell clump (b) from IUL observed under inverted microscope.

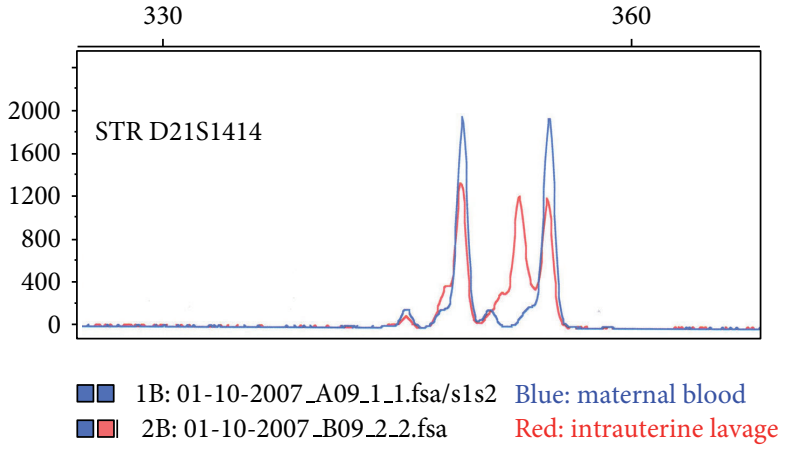

(a)

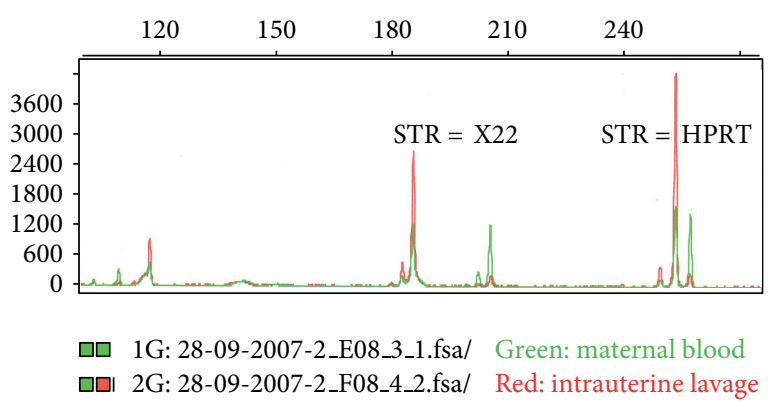

(b)

FIgURE 2: (a) Electrophoretogram showing the comparison of maternal and fetal peaks after amplification of DNA for the STR marker D21S1414. Triallelic pattern in a fetus with trisomy 21. (b) Monosomy X resulting from paternal nondisjunctionin the IUL there is only one allele (inherited from the mother) for each of the two selected STRs (X22 and HPRT).

the study. For instance it can be seen (Figure 2(b)) that in the case of monosomy $\mathrm{X}$ the single allele present in the fetus for each of the X-related STRs was present also in the mother, thus strongly suggesting paternal nondisjunction as the causative event of the aneuploidy; conversely, in the case of trisomy 21 presented in Figure 2(a) two out of the three alleles of the STR D21S1414 are found in the mother, and this finding (corroborated also by data not shown, relative to all the other STRs specific to chromosome 21) implies that trisomy resulted from maternal nondisjunction.

\section{Discussion}

In recent years earlier and safer alternatives to amniocentesis and CVS have been pursued. Ideally, fetal or trophoblastic cells should be obtained early in pregnancy by a safe procedure, be easily detected and isolated and then analysed by a reliable method. The presence of trophoblastic cells in TCC samples has been repeatedly confirmed in most studies, although there are relevant and sometimes striking differences as to the rate at which trophoblastic cells are found, depending also on the methods used for sample collection. Indeed, TCCs have been collected by a number of different procedures involving either cervical mucus sampling or the flushing of the lower uterine pole $[5,14]$, and it has been argued that while trophoblasts could be present in the mucus plug as a result of either exfoliation or active migration [5], IUL might rather act as a mini-CVS [6]. This could explain in some measure the much higher rates of trophoblastic cells in IULs, as compared with mucus samples, that had been put forward in earlier studies and have finally found confirmation in a recent investigation aimed at comparing the two techniques in the same group of women [6]. IULs always contain a mixture of cells from the maternal genital tract, and the problem of selecting only trophoblasts for further genetic analysis has been overcame by performing micromanipulation under inverted microscope, a simple and undemanding procedure that yields trophoblastic elements in more than $80 \%$ of all IULs [9].

Regarding the methods for analysis, the introduction of the QF-PCR assay in prenatal diagnosis has represented a relevant advance since its use on both CVS and amniotic fluid samples allows the quick and reliable detection of numerical chromosomal abnormalities [12]. QF-PCR could give also a major contribution to the possible use of TCCs for the purposes of prenatal diagnosis; as a matter of fact, this approach enables the precise assessment of chromosome copy number in IULs from both male and female fetuses, since, unlike FISH and standard PCR amplification techniques, it relies on the analysis of DNA polymorphisms and can therefore 
TABLE 1: STR markers, with extension and position, used in the study.

\begin{tabular}{|c|c|c|c|c|}
\hline Marker & Label & Heterozygosity & Chromosome location & Known alleles in bp \\
\hline AMXY & 6-fam & - & Xp22.1-22.31-Yp11.2 & X 104 Y 109 \\
\hline SRY & 6-fam & - & Yp11.2 & Y 463 \\
\hline $\mathrm{X} 22$ & 6-fam & 0.91 & Xq28 Yq (PAR2) & $\begin{array}{c}189-194-199-204-209-214-219-224-226- \\
229-234-239-242-247-253\end{array}$ \\
\hline DXYS218 & PET & 0.65 & Xp22.32 Yp 11.3 (PAR1) & 266-270-274-278-282-286-290-294 \\
\hline HPRT & 6-fam & 0.75 & Xq26.1 & $\begin{array}{c}268-272-276-278-280-284-288-292-296- \\
300-313\end{array}$ \\
\hline DXS6803 & VIC & 0.68 & $\mathrm{Xq12-Xq21.33}$ & 106-110-114-118-120-124-128 \\
\hline DXS6809 & VIC & 0.75 & $\mathrm{Xq}$ & $\begin{array}{c}238-242-246-250-252-254-258-260-262- \\
266-268-270-274\end{array}$ \\
\hline DXS8377 & NED & 0.85 & $\mathrm{Xq} 28$ & $\begin{array}{c}213-216-219-222-225-228-238-241-244- \\
248-252\end{array}$ \\
\hline SBMA & NED & 0.75 & $\mathrm{Xq} 11.2-\mathrm{Xq} 12$ & $\begin{array}{c}166-169-172-175-178-181-184-187-190- \\
193-196-199-202-205-208-211\end{array}$ \\
\hline $\mathrm{D} 21 \mathrm{~S} 1414$ & 6-fam & 0.85 & $21 \mathrm{q} 21$ & $\begin{array}{c}328-330-334-338-342-346-350-352-354- \\
356-358-360-362-443\end{array}$ \\
\hline $\mathrm{D} 21 \mathrm{~S} 1411$ & VIC & 0.93 & $21 \mathrm{q} 22.3$ & $\begin{array}{c}246-262-266-274-278-282-286-290-294- \\
298-302-306-316-319\end{array}$ \\
\hline D21S1446 & PET & 0.77 & 21q22.3-ter & $200-204-208-212-214-218-220-224-228$ \\
\hline D21S1437 & PET & 0.78 & $21 \mathrm{q} 21.1$ & $120-124-128-132-136-140-144$ \\
\hline D21S1008 & 6-fam & 0.70 & $21 \mathrm{q} 22.1$ & $196-200-204-208-212-216-220$ \\
\hline D21S1412 & 6-fam & 0.73 & $21 \mathrm{q} 22.2$ & $384-388-392-396-400-406-410-414-418$ \\
\hline D21S1435 & VIC & 0.75 & $21 \mathrm{q} 21$ & $142-168-172-176-180-184-188$ \\
\hline D18S391 & VIC & 0.75 & 18 pter-18p11.22 & $144-148-152-156-160-164-168$ \\
\hline D18S390 & VIC & 0.75 & $18 \mathrm{q} 22.2$ & $398-402-406-410-414-418-422-426-430$ \\
\hline D18S535 & NED & 0.82 & $18 \mathrm{q} 12.2$ & $126-130-134-138-142-146-148-152-156$ \\
\hline D18S386 & NED & 0.89 & $18 \mathrm{q} 22.1$ & $\begin{array}{c}319-330-334-338-342-344-350-354-358- \\
362-366-370-372-376-380-387\end{array}$ \\
\hline D18S858 & PET & 0.66 & $18 \mathrm{q} 21.1$ & 186-190-192-196-200-204 \\
\hline D18S499 & 6-fam & 0.72 & $18 \mathrm{q} 21.32-\mathrm{q} 21.33$ & $386-392-396-400-404-408$ \\
\hline D18S1002 & 6-fam & 0.80 & $18 \mathrm{q} 11.2$ & $122-130-134-138-142$ \\
\hline D13S631 & VIC & 0.78 & $13 q 31-32$ & 192-196-200-204-208-212-215-218 \\
\hline D13S634 & VIC & 0.85 & $13 \mathrm{q} 14.3$ & $\begin{array}{c}460-464-466-470-474-478-482-484-486- \\
490-496-500\end{array}$ \\
\hline D13S258 & NED & 0.89 & $13 q 21$ & $\begin{array}{c}230-232-234-236-238-240-242-244-248- \\
265-267-269-271-273-277-279-281\end{array}$ \\
\hline D13S305 & PET & 0.75 & $13 q 12.1-13 q 14.1$ & $426-430-434-438-442-446-450-454-458$ \\
\hline D13S628 & 6-fam & 0.70 & $13 q 31-q 32$ & 436-440-444-448-452-456-460-464 \\
\hline D13S742 & VIC & 0.75 & $13 \mathrm{q} 12.12$ & $254-258-262-266-268-270-274$ \\
\hline
\end{tabular}

discriminate the maternal and trophoblastic origin of the cells.

The results of this study on the one hand confirm that IUL samples are a valuable source of trophoblastic cells that can be easily isolated [10] and on the other hand suggest that aneuploidies such as trisomy 21 and monosomy $\mathrm{X}$, that account for a remarkable proportion of all clinically relevant chromosomal disorders, can accurately be detected in these cells by a QF-PCR assay. Our results are important, as, in spite of the body of research on TCCs, very little had been previously reported on the detection of chromosomal or genetic disorders using these cells [15-19], which is no doubt a crucial point in view of the possible clinical use of the procedure.

A limitation of the approach described in this study, and in particular of the QF-PCR analysis, is that only numerical abnormalities of selected chromosomes can be detected, but only standard karyotype enables full evaluation of all numerical as well as structural alterations. This drawback of the QF-PCR procedure is, however, outweighed by many advantages such as quickness of results and minor lab costs. Although there is a preliminary study on continuing pregnancies reporting no complications following IUL [20], further research is required to precisely assess the safety 
of this sampling technique; in an ongoing study IUL is being performed in a group women scheduled for TOP at the time of first booking in order to have a short yet significant period of followup for possible procedure-related complications.

\section{Acknowledgment}

The authors would like to thank the "Ente Cassa di Risparmio di Firenze" for financial support.

\section{References}

[1] D. Wilson, B. McGillivray, D. Kalousek et al., "Multicentre randomised clinical trial of chorion villus sampling and amniocentesis," The Lancet, vol. 1, no. 8628, pp. 1-6, 1989.

[2] D. W. Bianchi, "Prenatal diagnosis by analysis of fetal cells in maternal blood," Journal of Pediatrics, vol. 127, no. 6, pp. 847-856, 1995.

[3] Y. M. D. Lo, "Fetal DNA in maternal plasma: biology and diagnostic applications," Clinical Chemistry, vol. 46, no. 12, pp. 1903-1906, 2000.

[4] L. B. Shettles, "Use of the Y chromosome in prenatal sex determination," Nature, vol. 230, no. 5288, pp. 52-53, 1971.

[5] M. Adinolfi and J. Sherlock, "First trimester prenatal diagnosis using transcervical cells: an evaluation," Human Reproduction Update, vol. 3, no. 4, pp. 383-392, 1997.

[6] R. Cioni, C. Bussani, B. Scarselli, S. Bucciantini, M. Marchionni, and G. Scarselli, "Comparison of two techniques for transcervical cell sampling performed in the same study population," Prenatal Diagnosis, vol. 25, no. 3, pp. 198-202, 2005.

[7] R. Cioni, C. Bussani, B. Scarselli et al., "Detection of fetal cells in intrauterine lavage samples collected in the first trimester of pregnancy," Prenatal Diagnosis, vol. 22, no. 1, pp. 52-55, 2002.

[8] T. Ergİn, V. Baltaci, H. B. Zeyneloğlu, E. Hakan Duran, M. H. Ergenelİ, and S. Batioğlu, "Non-invasive early prenatal diagnosis using fluorescent in situ hybridization on transcervical cells: comparison of two different methods for retrieval," European Journal of Obstetrics Gynecology and Reproductive Biology, vol. 95, no. 1, pp. 37-41, 2001.

[9] C. Bussani, R. Cioni, B. Scarselli et al., "Strategies for the isolation and detection of fetal cells in transcervical samples," Prenatal Diagnosis, vol. 22, no. 12, pp. 1098-1101, 2002.

[10] C. Bussani, B. Scarselli, R. Cioni, S. Bucciantini, and G. Scarselli, "Use of the quantitative fluorescent-PCR assay in the study of fetal DNA from micromanipulated transcervical samples," Molecular Diagnosis, vol. 8, no. 4, pp. 259-263, 2004.

[11] R. Cioni, C. Bussani, S. Bucciantini, and G. Scarselli, "Fetal cells in a transcervical cell sample collected at 5 weeks of gestation," Journal of Maternal-Fetal and Neonatal Medicine, vol. 18, no. 4, pp. 271-273, 2005.

[12] V. Cirigliano, G. Voglino, A. Marongiu et al., "Rapid prenatal diagnosis by QF-PCR: evaluation of 30,000 consecutive clinical samples and future applications," Annals of the New York Academy of Sciences, vol. 1075, pp. 288-298, 2006.

[13] V. Cirigliano, M. Ejarque, C. Fuster, and M. Adinolfi, "X chromosome dosage by quantitative fluorescent PCR and rapid prenatal diagnosis of sex chromosome aneuploidies," Molecular Human Reproduction, vol. 8, no. 11, pp. 1042-1045, 2002.

[14] F. Z. Bischoff and J. L. Simpson, "Endocervical fetal trophoblast for prenatal genetic diagnosis," Current Opinion in Obstetrics and Gynecology, vol. 18, no. 2, pp. 216-220, 2006.
[15] B. Tutschek, J. Sherlock, A. Halder, J. Delhanty, C. Rodeck, and M. Adinolfi, "Isolation of fetal cells from transcervical samples by micromanipulation: molecular confirmation of their fetal origin and diagnosis of fetal aneuploidy," Prenatal Diagnosis, vol. 15, no. 10, pp. 951-960, 1995.

[16] J. Sherlock, A. Halder, B. Tutschek, J. Delhanty, C. Rodeck, and M. Adinolfi, "Prenatal detection of fetal aneuploidies using transcervical cell samples," Journal of Medical Genetics, vol. 34, no. 4, pp. 302-305, 1997.

[17] M. Adinolfi, A. Davies, S. Sharif, P. Soothill, and C. Rodeck, "Detection of trisomy 18 and Y-derived sequences in fetal nucleated cells obtained by transcervical flushing," The Lancet, vol. 342, no. 8868, pp. 403-404, 1993.

[18] F. Maggi, F. Berdusco, R. Liuti et al., "First-trimester chromosome diagnosis by lavage of the uterine cavity," Prenatal Diagnosis, vol. 16, no. 9, pp. 823-827, 1996.

[19] A. Massari, G. Novelli, A. Colosimo et al., "Non-invasive early prenatal molecular diagnosis using retrieved transcervical trophoblast cells," Human Genetics, vol. 97, no. 2, pp. 150-155, 1996.

[20] S.-D. Chang, S.-L. Lin, K.-K. Chu, and B.-L. Hsi, "Minimallyinvasive early prenatal diagnosis using fluorescence in situ hybridization on samples from uterine lavage," Prenatal Diagnosis, vol. 17, no. 11, pp. 1019-1025, 1997. 

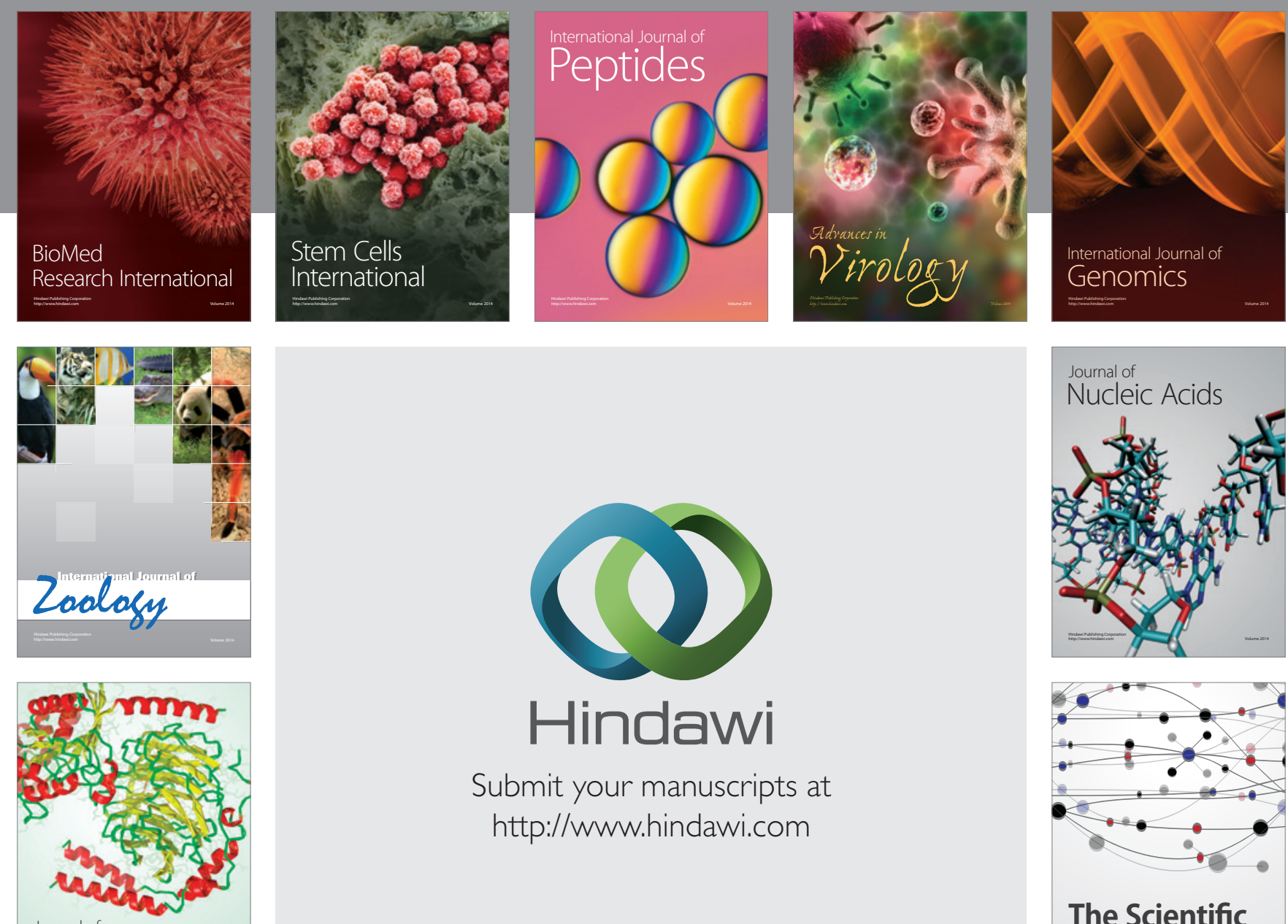

Submit your manuscripts at

http://www.hindawi.com

Journal of
Signal Transduction
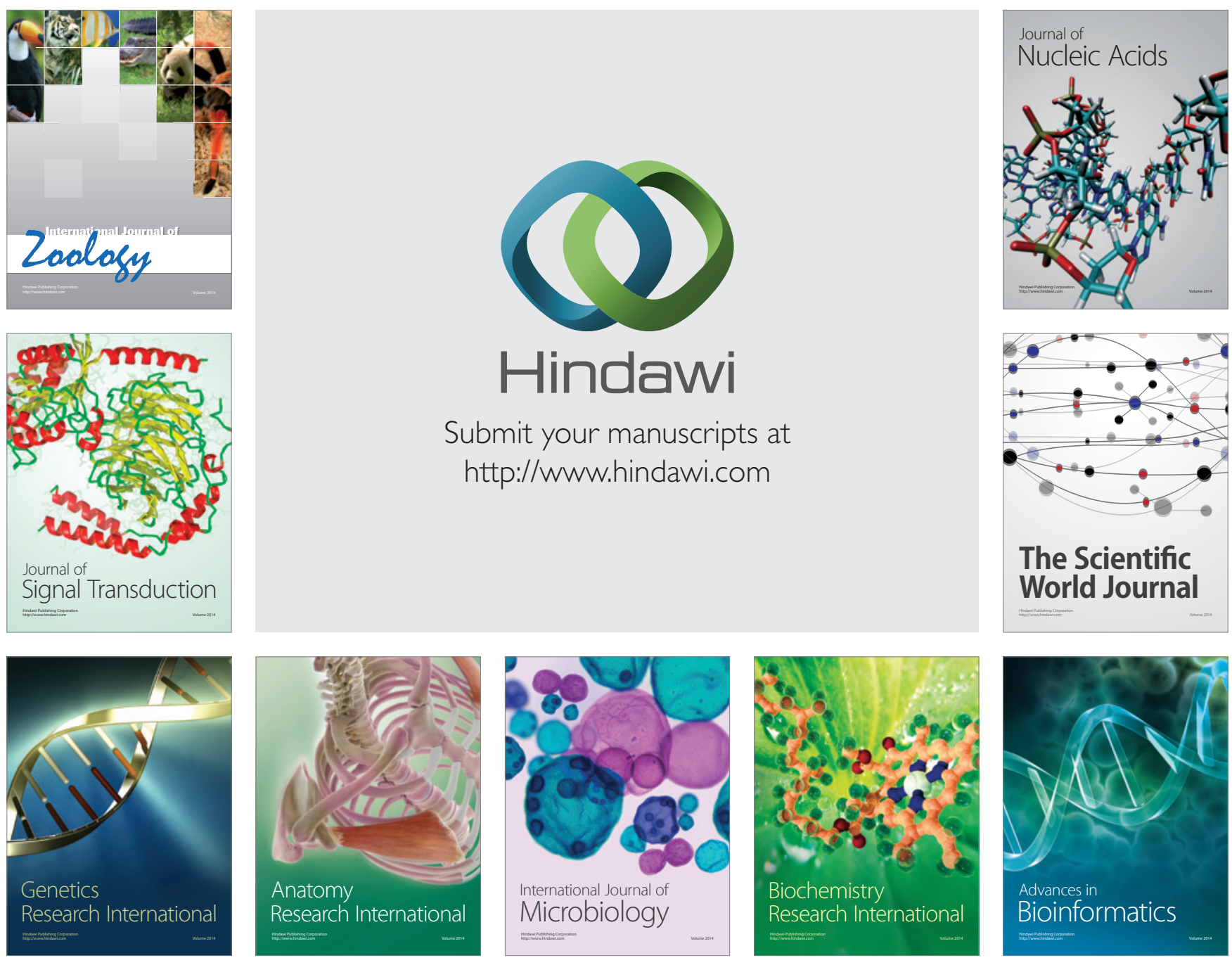

The Scientific World Journal
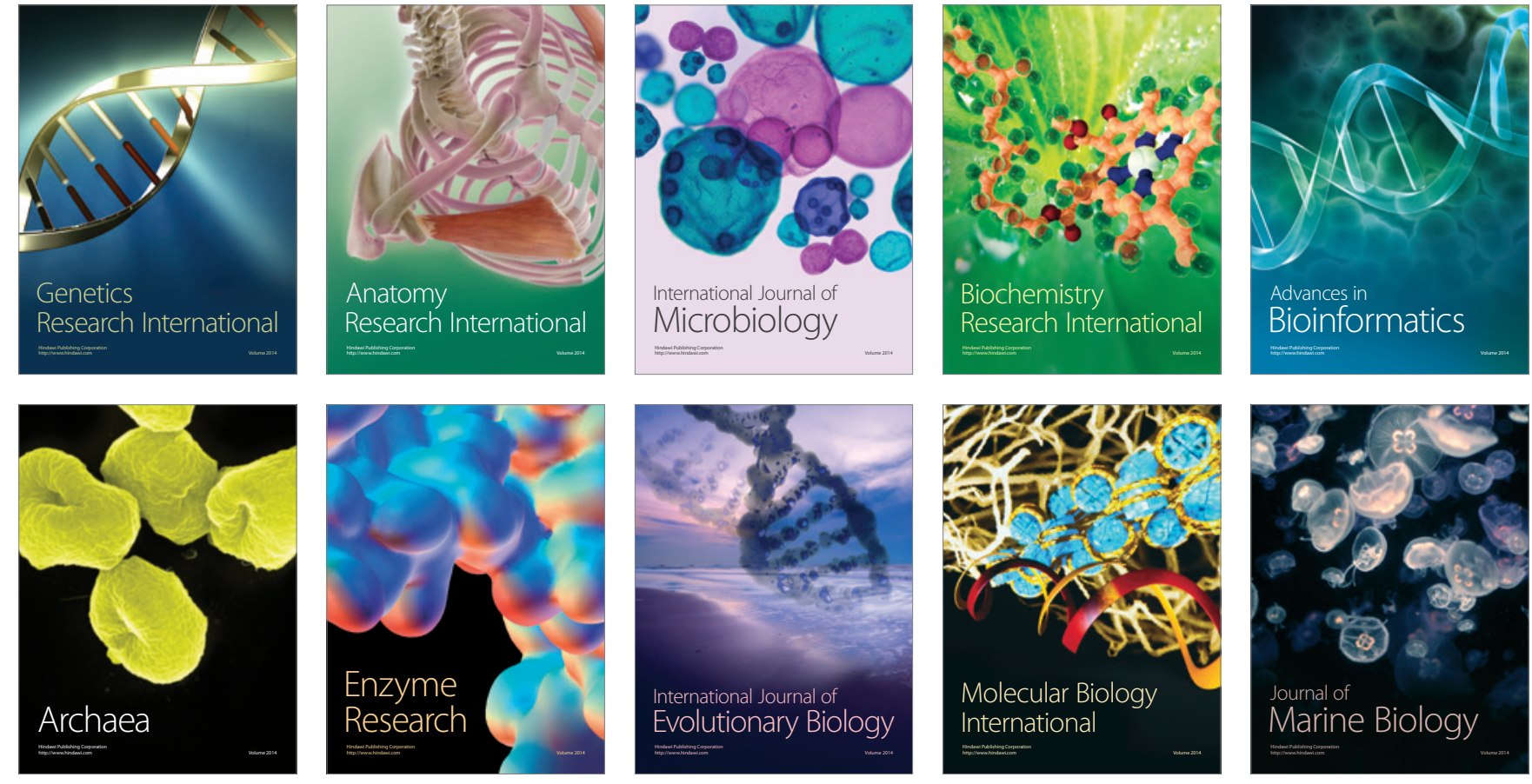